\title{
DROUGHT RISK MANAGEMENT IN MEXICO: PROGRESS AND CHALLENGES
}

\author{
D. ORTEGA-GAUCIN, M. LÓPEZ PÉREZ \& F.I. ARREGUÍN CORTÉS \\ Mexican Institute of Water Technology.
}

\begin{abstract}
Drought is one of the most complex natural phenomena, which affects the most people in the world. In Mexico, drought has been a recurrent and persistent problem throughout its history. In recent years, drought has affected large agricultural areas and rural communities, leading to severe imbalances in the regional and national economies, as occurred during the 2011-2012 drought, the most severe of the last 70 years. Therefore, in this paper an analysis of the measures that have recently been implemented to cope with drought in Mexico, which highlights the beginning of the transition from a reactive approach based on the crisis management towards a proactive approach aimed to risk management, with the implementation of the National Program Against Drought (PRONACOSE, for its acronym in Spanish) launched in 2013 is presented. So, in this paper, the components of this program are presented, along with a brief description of the Programs of Preventive and Mitigation Drought Measures (PMPMS, for its acronym in Spanish), which have been formulated as an integral part of PRONACOSE for each of the 26 basin councils in the country. Similarly, some of the main future challenges in drought management and research needs identified during the formulation of the PMPMS are exposed. We concluded that there is no way to avoid a drought but there are ways to mitigate its impacts and reduce losses of those affected by the phenomenon. Drought risk can't be completely eliminated, but preventive actions implemented in the future will be useful to mitigate its effects.

Keywords: disaster, drought, mitigation, planning, prevention, risk management, vulnerability.
\end{abstract}

\section{INTRODUCTION}

Drought is a recurring weather phenomenon defined by a rainfall reduction regarding to what is considered as normal for a specific zone. It does not show a defined epicenter or a trajectory but it expands in an irregular form through time and space which makes the available water not to be enough to fulfill the various human and ecosystems needs.

Drought is considered as one of the most complex natural phenomena and the one that affects more people worldwide. Apart from its direct effects on production, it can also affect the water supply for human consumption, as well as making the population emigrate and, in some serious cases, causing famines and deaths. Unlike other disasters that are associated to natural phenomena whose impacts occur at a local level and in a short-term, droughts span large geographical areas and their consequences could remain for many years having a negative effect on the quality of life and development of the affected population.

In Mexico, the drought problem has been a recurring and persistent issue throughout its history, as the documented records show about the droughts that took place even before the Spanish colonization. Even though the exact dates are not recorded, it is known that there were dry periods in the ancient Mexico that caused famine, migration and death that disrupted not only the farming activities, but the everyday life of the communities. There has 


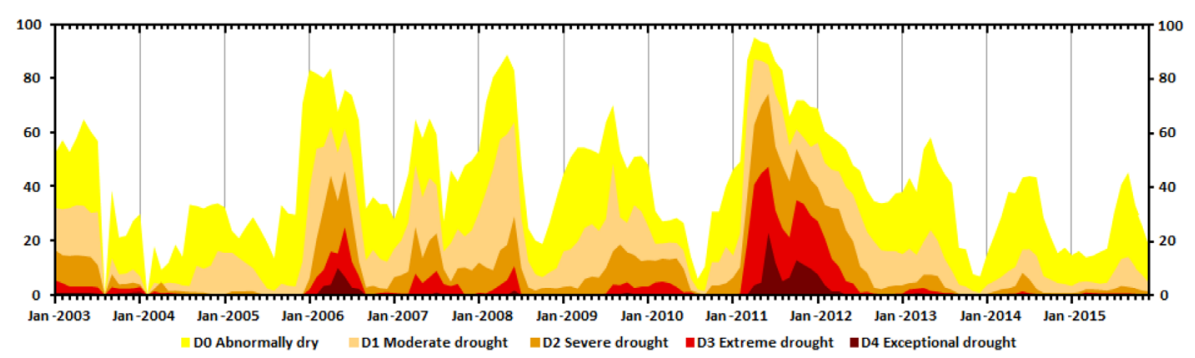

Figure 1: Percentage of affected area by drought in Mexico: from January 2003 to December 2015 [3].

been a record in the latest decades in Mexico of a lack of rainfall during many years (Fig. 1), whose frequency and harshness have increased, being most likely due to global climate change [1].

The recent years' droughts have affected great extensions of farming lands and country areas favoring severe problems in the local and national economies, just as it occurred during the 2011-2012 drought, the most severe one of the last 70 years that affected more than $80 \%$ of the national territory (Fig. 2). The said drought caused an economic loss in the agricultural production that surpassed the 16 billion Mexican pesos (around 1.3 billion American dollars) and it is calculated that the total losses in the different economic sectors corresponded to $10 \%$ of the national gross domestic product. It is estimated that 48 million Mexican people went through the consequences of the disaster in arid, semi-arid and sub-humid zones, which was a problem that affected two out of three cultivated hectares and caused the death of thousands of livestock [2].

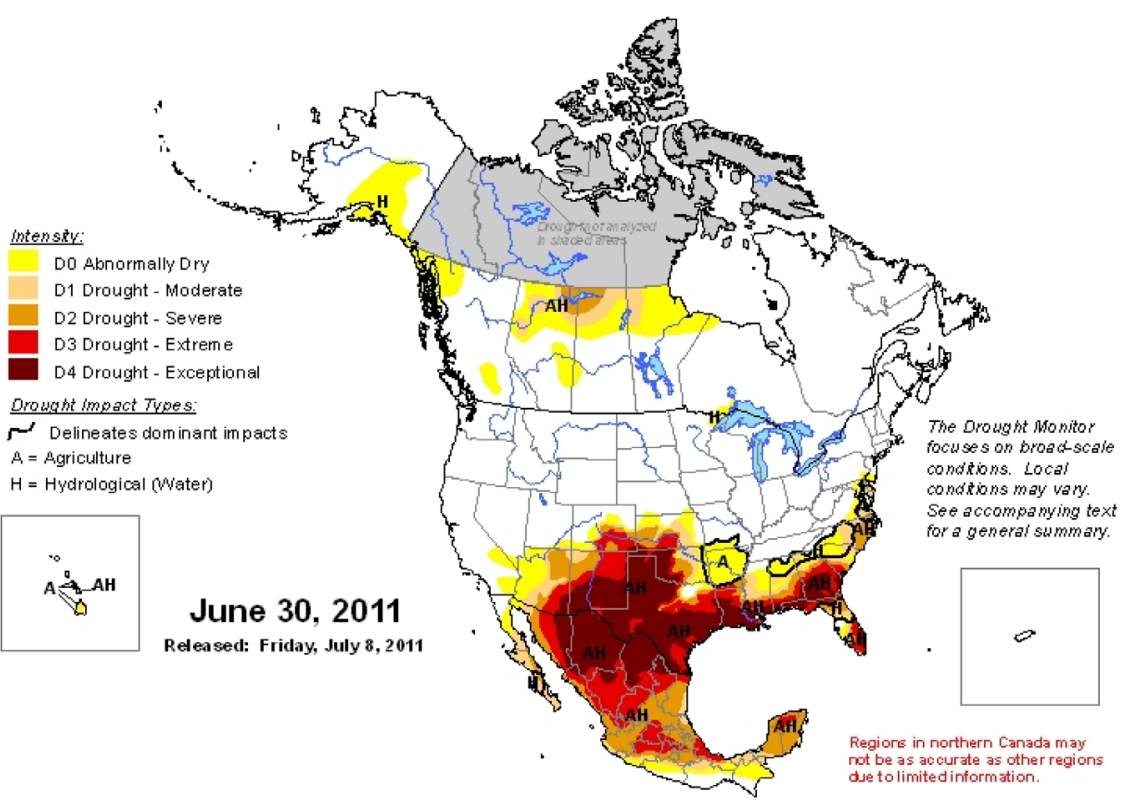

Figure 2: Areas of Mexico, United States and Canada affected by drought during June 2011 [4]. 
In this context, this paper has the objective of making an exposition and analysis of the measures that have been implemented to cope with drought during the last years in Mexico, where is remarkable the onset of the process for the transition from a reactive approach based on the crisis management towards a proactive approach that is focused on the drought risk management.

\section{POLITICS AND INSTITUTIONS COPING WITH DROUGHT IN MEXICO}

Internationally, there are basically two approaches that pay attention to the drought issue and its side effects: risk management and crisis management. The difference lies in the response time and the adopted measures in each case. On one side, risk management is a proactive approach focused on the creation of strategies to be implemented ahead of a drought occurrence; all of this to prevent and mitigate the risk level exposition and, therefore, the vulnerability to impacts. This approach tries to increase the systems' resilience (the capacity to recover) through structural and non-structural measures on a continuous basis. On the other hand, crisis management is a reactive approach based on the implementation of response measures and actions after knowing the havoc wrought by drought. This approach is implemented in emergency situations and the probabilities of giving solutions that are technically and economically efficient are considerably reduced since the actions are taken according to the damages caused to the population without even evaluating the available options adequately. Such approach tends to support the dependence on the relief measures to face an emergency instead of strengthening the resilience $[5,6]$.

In Mexico, the attention to droughts had been basically reactive until the year 2012, where risk management had been paramount but the risk had not. When there is a severe drought, such as the one of 2011, the first reaction of the local authorities was that of requesting a drought natural disaster declaration before the National Water Commission (CONAGUA, for its acronym in Spanish) through which they had access to the traditional federal government support from the National Fund for Natural Disasters (FONDEN, for its acronym in Spanish). This fund was established in the late '90s of the last century as a budgetary mechanism to support the rehabilitation of the federal and local infrastructure affected by "natural" disasters and even though it has been a good resource of financing to meet the emergency needs caused by drought and other disasters in the short term, it is not completely suitable or enough as an all-embracing strategy to manage the risk of a lengthy and widespread drought, such as the one that recently occurred in the country.

In parallel with this, coping with the emergency caused by drought, the federal government and the local authorities tend to implement various emergency programs of humanitarian and agricultural support, some of them such as: water delivery through tankers to the affected communities, groceries distribution to the rural population, provision of dietary supplements for cattle, supply of checks or cash to the affected, etc. Such actions do not have a welldefined long-term purpose, therefore, they are not designed to be comprehensive plans with specific strategies that could be implemented in future drought events [7]. At the same time, it has been noticed that there is a lack of coordination when an emergency arises amongst the different levels of government and offices that have the responsibility of implementing the programs or distributing the economic supports, hence there is a constant duplicity or multiplicity of actions and assigned resources (and also some gaps or voids where the need of the population are not well met) which makes the performance of the authorities not efficient or effective enough to face the contingency. 
That is the reason why it is necessary to admit that in Mexico, in the last decades, drought has been treated in a reactive manner as if it was a "natural disaster", similar to others caused by other natural phenomena, such as earthquakes or hurricanes, but the effects caused by droughts are very different from those caused by such phenomena (generally speaking, droughts have a slow and gradual beginning and it is not known when they end, their damages are not structural and they extend to large geographical areas) then they need a specific treatment to its attention.

Fortunately, the first signals of change in the drought attention and secondary effects approach can be seen in the country. For instance, the federal government through the Ministry of Agriculture, Livestock, Rural Development, Fisheries and Food (SAGARPA, for its acronym in Spanish) has been in recent years, building a catastrophic insurance national strategy with the support of the state government, by transferring each year a $80 \%$ of the approved budget by the Chamber of Deputies for contingencies attention, insurance services, either by the states governments or directly as a protection mechanism for the producers that do not have an insurance, through the Catastrophic Agricultural Coverage Insurance of the Element of Attention to Natural Disasters (CADENA, for its acronym in Spanish).

Likewise, due to the great economic and material losses that farmers, stock raisers and the water system distribution have had, starting the year 2013, it was decided that in Mexico a public policy should be changed and adopted to manage droughts in a different manner, going from a reactive attention to a proactive approach, one that is preventive and based on risk management, such as described in the following paragraphs.

\section{NATIONAL PROGRAM AGAINST DROUGHT (PRONACOSE)}

The severe drought that affected Mexico during the years 2011 and 2012, as well as the socioeconomic and environmental impacts that were brought about by the phenomenon, led the federal government to publish in the Federal Official Gazette [8], on January 25, 2012, the "Agreement with which actions are ordered to mitigate the drought effects that manifold states are suffering", through which the head of the federal executive ordered to several offices of the federal public administration the implementation of actions to mitigate the drought effects, the speeding up of the use of public resources and the execution of public works in order to address the consequences of the said meteorological phenomenon.

Subsequently, on November 22, 2012, the federal government published on the Federal Official Gazette [9] the "Guidelines that establish the criteria and mechanisms to issue general agreements for emergency situations due to droughts, as well as the preventive and mitigation measures that shall be implemented by the national waters users to achieve an efficient use of the liquid during the drought", through which the applicable criteria and mechanisms were established for the CONAGUA to issue the general agreements for emergencies due to a drought occurrence, as well as to suggest to the national waters users, drought preventive and mitigation measures according to which an efficient use of water can be accomplished so it can be protected.

The previous guidelines were used as a framework for that the president of the republic to announce on January 10, 2013, the implementation of the National Program Against Drought (PRONACOSE, for its acronym in Spanish), and designating CONAGUA as the responsible for its overall coordination. The PRONACOSE has the objective of implementing a number of preventive and mitigation actions focused on the reduction of the population vulnerability before a drought. This program focuses on the development of the actions to act timely in possible contingencies, and it is formed by three core points: 
a. Planning process that includes: drought monitoring to issue early warnings and the drawing up of the prevention and mitigation programs by basins and user groups;

b. Attention to the affected population by the phenomenon, even during the program planning process, that includes: the establishment of a legal administrative protocol to create a declaration of drought emergency and the issuing and implementation of the general agreements to guarantee the water supply for human consumption while the event lasts and;

c. Organization, that includes the coordination of the allocation of the resources of the FONDEN and of the various federal programs as well as the permanent review of the said programs and their operative rules to have an efficient and effective implementation of the resources to mitigate the drought effects.

The Intersecretarial Commission on Droughts and Floods (CIASI, for its acronym in Spanish) is in charge of the implementation and following-up of the PRONACOSE. This commission was created on a permanent basis through an agreement that was published by the federal government in the Federal Official Gazette [10] on April 5, 2013, and its objective is that of the actions coordination between offices and local authorities of the federal public administration, related to the risk analysis and the implementation of measures of prevention and mitigation of extraordinary meteorological phenomena and the consequences that they bring about, such as droughts and floods. This Intersecretarial Commission determines and watches the actions and works of the agencies that compose it to prevent and mitigate the drought. In the meantime, the evaluation and improvement of the PRONACOSE is in charge of a Drought Expert Committee (CTES, for its acronym in Spanish) that is formed by researchers and academicians from various universities and research centers of the country.

As an integral part of the PRONACOSE, since 2013, the National Meteorological Service (SMN, for its acronym in Spanish) releases timely alerts and monitors the evolution of the drought by publishing fortnightly about the affected areas and the level of severity of the phenomenon at a basin, state and municipality level regarding the severity degree defined by the North American Drought Monitor (NADM): abnormally dry (D0), moderate drought (D1), severe drought (D2), extreme drought (D3) and exceptional drought (D4). Likewise, the Standardized Precipitation Index (SPI) is determined weekly for the main climate stations of the country. These results are permanently published on the SMN website (smn.conagua.gob.mx).

\section{PROGRAMS OF PREVENTIVE AND MITIGATION DROUGHT MEASURES (PMPMS)}

As an integral part of the PRONACOSE, it has already been formulated the first version of the Programs of Preventive and Mitigation Drought Measures (PMPMS, for its acronym in Spanish) for each one of the 26 basin councils that are conformed in the country (Fig. 3 ).

The basin councils are authorities designed for the water co-management. They are mixed integration collegiate bodies between the representatives of the three government levels and the citizenry to contribute in the integrated water resource management and to restore the balance between its availability and exploitation.

For the purpose of planning the formulation of the PMPMS, it was named in each basin council an Executive Technical Group (GTD, for its acronym in Spanish) as an organizational figure focused to that end. Each GTD was formed by representatives of the authorities and the different sectors of water users (agricultural, urban public, industrial, etc.), who actively participated in a cooperative and interactive process in the formulation of the programs. 


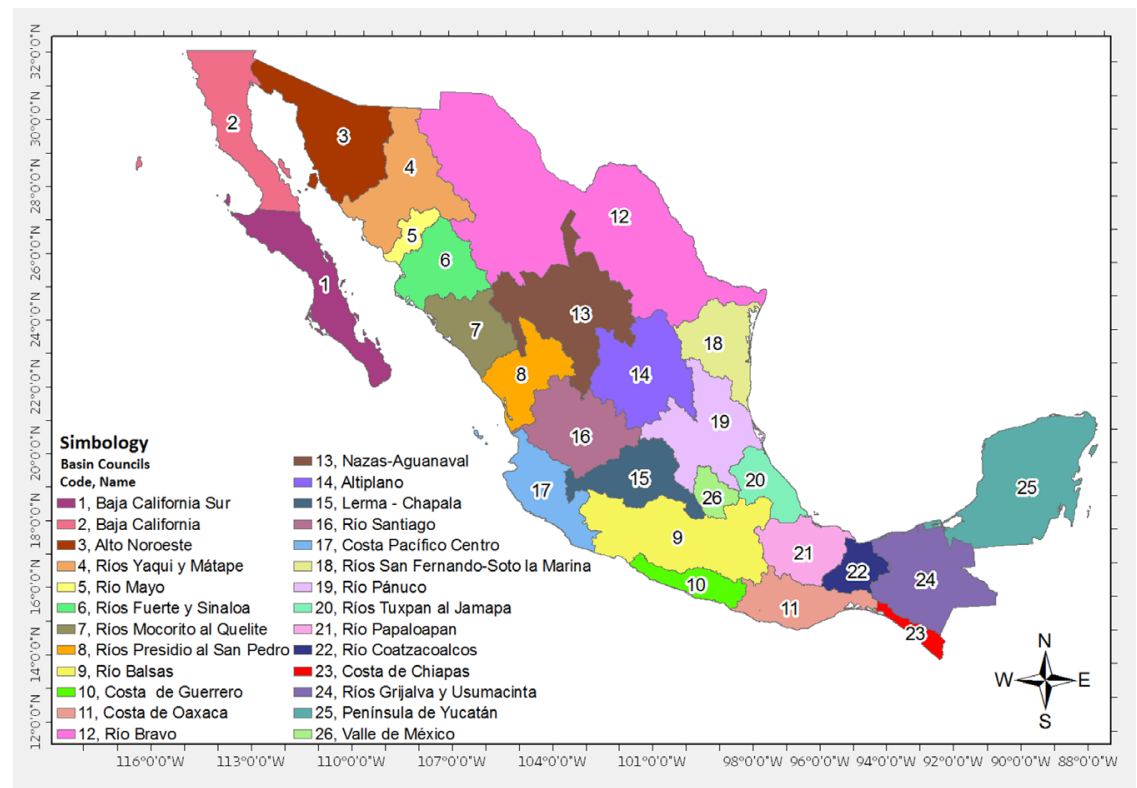

Figure 3: Geographical demarcation of the 26 basin councils in Mexico (adapted from CONAGUA [11]).

In that way, the PMPMS has the general objective of minimizing social, economic and environmental impacts of possible drought situations and have been conceived as planning instruments that will serve as the basis for the right decision making within the basin councils about the drought in the different sectors of the water users. The process for the elaboration of each one of the 26 PMPMS was formed of eight steps (Fig. 4): (1) The program objectives and the guiding principles were established within the basin councils; (2) The characterization of the historical droughts and their impacts is carried out; (3) The evaluation of the current vulnerability to droughts was executed; (4) The strategies of mitigation and response to a drought were specified; (5) The identification of the different stages of the drought and the corresponding signs and response objectives was performed; (6) A detailed program on the responses for each stage of the drought was fulfilled; (7) An indicator system for the following-up and evaluation of the program was prepared; (8) A reviewing and updating plan of the document was determined.

In summary, each one of the PMPMS includes the following: the physical and socioeconomical characterization of the basin at issue; the analysis of the historical droughts and their impacts; the evaluation of the current vulnerability to droughts; the stages and signs of the drought and the measures that can be implemented within the basin councils to face the drought in three ways: before the phenomenon occurs (strategic measures), when it is starting (tactical measures) or when it is already happening (emergency measures), such as it is described below [13]:

a. Strategic measures. These types of measures mean actions taken in a long term (having duration of more than 2 years), and they normally have an institutional and infrastructural nature that are part of the hydrological planning. For example: the building of infra- 


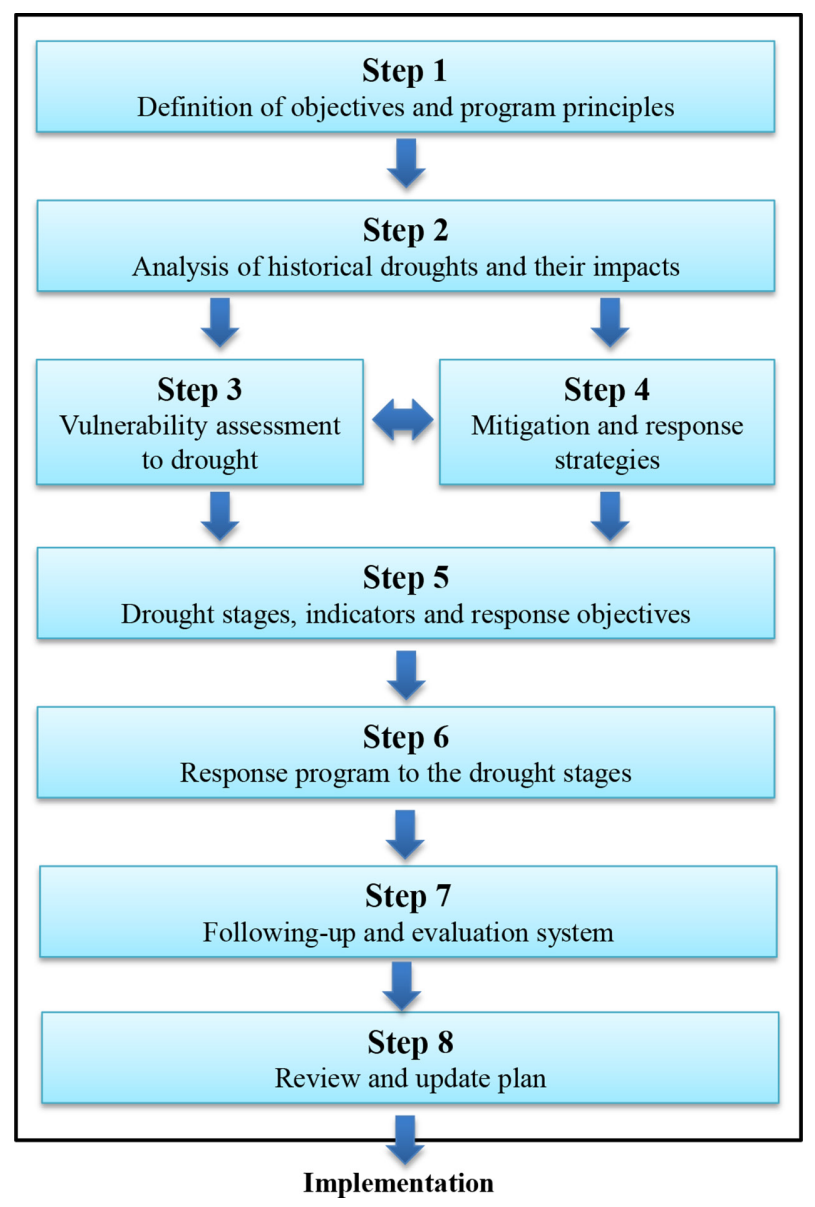

Figure 4: PMPMS elaboration process development chart (adapted from IMTA [12]).

structure to keep water or the agreement and regulations development for its distribution amongst the various catchment users.

b. Tactical measures. They are short-term actions (with duration going from some months up to 2 years) that are planned and validated early within the drought program. They shall be activated at yellow and red alerts. For example: when there is an increase in water prices or the reutilization of grey waters for garden irrigation or any other non-priority uses.

c. Emergency measures. They are actions taken in a very short-term (with a duration of weeks or months) and their objective is that of facing the water deficit caused by a drought when it is already there or when it is already at an advanced stage and they will vary according to its seriousness and the level of effects in the catchment. For example: water distribution through tankers amongst the population or its rationing and reduction for certain purposes.

It is important to mention that the distinction between the strategic measures, the tactical measures and the emergency measures depends on the synchronization and the manner that 
each basin council implements them. For instance, the renovation of wells (i.e., the restoration of the water production in the wells to its most efficient manner through various treatments and methods), it can be considered as a strategic measure if it is done on an everyday basis to assure that the wells are in good working conditions when there is a drought or it can be also a tactical measure in case it is done after a drought declaration. Ultimately, it can also be an emergency measure if it is carried out when the drought is in an advanced stage and it is required to extract water from the subsoil urgently.

In addition, in the PMPMS there is a specification of a foundation for implementing the actions, distinguishing those for the water supply that are related to works and distribution systems; and on the side of demand, the ones that have an impact on the use and consumption by the users. This is known as the management of demand and supply water when there is a drought.

\section{FUTURE CHALLENGES IN DROUGHTS MANAGEMENT}

As it was already stated, the basic fundamentals of PRONACOSE are the "drought guidelines" that were published in the Federal Official Gazette [9] on November 22, 2012. Nevertheless, it is necessary to move from these guidelines to a specific legislation in terms of drought. It is undoubtedly that an efficient strategy of mitigation of drought needs a specific law due to the lack of presence of the risk management subject in the National Water Law of Mexico. Such legislation shall guarantee the flow of information between the basic elements of the program and specify accurately the commitments of each institution related to the exploitation of the water resources. Likewise, the three government levels must be included (not only the federal offices) and to establish the relationships and responsibilities between institutions and organizations that manage the water, as well as the sanctions that shall be enforced on the lack of action or the noncompliance of the commitments.

Likewise, to assure the compliance of the actions that are part of the PRONACOSE, it is necessary to establish a follow-up and evaluation system of the PMPMS (both at a basin councils and cities, states and municipalities level) that allows having a control and record of the various preventive and mitigation measures that are implemented through the use of appropriate indicators. There is evidence that show that even the most elaborated or detailed drought management plan can be inefficient if the officers in charge of the water management cannot or do not want to execute the specified measures besides the fact that this type of plan or program are normally forgotten after the contingency has ended.

Additionally, it is necessary to implement nationwide a broad campaign of communication, information and dissemination of information on droughts and their consequences in society, as there are frequently mass media campaigns whose purpose is that of encouraging a "water culture" amongst the population, nevertheless, the drought subject has never been included as a part of those campaigns.

It is also of the utmost importance that the SMN starts generating scenarios (not forecasts) of droughts, such as the ones that the National Oceanic and Atmospheric Administration (NOAA) develops with the sole purpose of foreseeing possible situations of drought persistence and contingencies due to the scarcity and lack of water. And finally, it is important to continue the development of various lines and projects of research related to droughts that tackle the subject from different approaches and knowledge fields (climatology, engineering, agronomy, biology, sociology, education, etc.), with the purpose of improving the under- 
standing of the phenomenon and identifying better practices to prevent and mitigate its socioeconomic and environmental impacts.

\section{CONCLUSIONS}

There is no manner to avoid a drought, but there are ways to mitigate its impacts and reduce the losses of those who are affected. Currently, Mexico is enveloped in a transition process that is going from a reactive approach centered in the management of the crisis caused by droughts to a preventive approach focused on the risk management. The aim of the National Program Against Drought is that of anticipating droughts by foreseeing solutions to satisfy the demand by avoiding situations of water shortage and conflicts between users for its use. The risk cannot be fully eliminated nevertheless the actions that are implemented in the future as part of this program will be useful to mitigate its effects while it is necessary to strengthen and implement measures that reduce the impacts caused by the lack of water in the short, medium and long terms.

It is expected then, that all these actions implemented by the federal government to cope with droughts, alongside the active participation of the state and local governments as well as the organized civil society, generate results from their efforts in a medium term.

\section{REFERENCES}

[1] Intergovernmental Panel on Climate Change (IPCC), Climate Change 2013: the Physical Science Basis, Summary for Policymakers, WMO/UNEP: Geneva, Switzerland, 33, 2013.

[2] National Institute for Statistics and Geography (INEGI), Estadísticas a propósito del día mundial contra la desertificación y la sequía, available at www.iieg.gob.mx/contenido/ GeografiaMedioAmbiente/INEGI_Diamundialcontraladesertificacionylasequia.pdf

[3] National Meteorological Service (SMN), Monitor de Sequía en México, available at www.smn.cna.gob.mx/index.php?option=com_content $\& v i e w=\operatorname{article} \& i d=20 \&$ Item $\mathrm{id}=74$

[4] National Oceanic and Atmospheric Administration (NOAA), North American drought monitor, available at www.ncdc.noaa.gov/temp-and-precip/drought/nadm/

[5] Knutson, C., Hayes, M. \& Phillips, T., How to reduce drought risk, available at www. drought.unl.edu/portals/0/docs/risk.pdf

[6] Zhang, Q., Kobayashi, Y., Howell, M.A. \& Zheng, Y., Drying up: What to do About Droughts in the People's Republic of China, with a Case Study from Guiyang Municipality, Gizhou Province, Asian Development Bank: Mandaluyong City, Philippines, 66, 2012.

[7] Ortega-Gaucin, D., Sequía en Nuevo León: Vulnerabilidad, Impactos y Estrategias de Mitigación, Instituto del Agua de Nuevo León: Apodaca, N.L, 222, 2012.

[8] Federal Official Gazette (DOF), Acuerdo por el que se instruyen acciones para mitigar los efectos de la sequía que atraviesan diversas entidades federativas, available at www. dof.gob.mx/nota_detalle.php?codigo $=5231010 \&$ fecha $=25 / 01 / 2012$

[9] Federal Official Gazette (DOF), Lineamientos que establecen los criterios y mecanismos para emitir acuerdos de carácter general en situaciones de emergencia por la ocurrencia de sequía, así como las medidas preventivas y de mitigación, que podrán implementar los usuarios de las aguas nacionales para lograr un uso eficiente del agua durante sequía, available at www.dof.gob.mx/nota_detalle_popup.php?codigo=5278695 
[10] Federal Official Gazette (DOF), Acuerdo por el que se crea la Comisión Intersecretarial para la Atención de Sequías e Inundaciones, available at www.dof.gob.mx/nota_detalle. php?codigo $=5294627 \&$ fecha $=05 / 04 / 2013$

[11] National Water Commission (CONAGUA), Programa Nacional Contra la Sequía, avalaible at www.pronacose.gob.mx

[12] Mexican Institute of Water Technology (IMTA), Guía para la Formulación de Programas de Prevención y Mitigación de Sequía, IMTA's Coordination of Hydrology: Jiutepec, Morelos, 56, 2013.

[13] National Water Commission (CONAGUA), Programa de Medidas Preventivas y de Mitigación de la Sequía. Consejo de Cuenca del Río Balsas, SEMARNAT: México, D.F., 246, 2013. 